\title{
Thinking in three dimensions
}

\section{John Launer}

I have had only few major "eureka" moments in my life. One of them was when I realised the difference between ordinary linear thinking and systems thinking. Since then I have spent quite a lot of my time teaching systems thinking in one form or another to doctors, psychologists, educators and others. Sometimes people can be turned off by the word systems because it sounds so mechanical, but once they overcome this distraction most people find systems thinking incredibly helpful. For some, it is like moving from a two dimensional world into a three dimensional one. For others, it is almost like a religious awakening.

Systems ideas have been around since the middle of the 20th century. They arose in many different disciplines including engineering, physics, biology and anthropology - all of which were trying to understand how complex systems worked through processes like feedback and homeostasis. The ideas are associated with a number of names that have largely been forgotten outside specialist disciplines, including Norbert Wiener, Heinz von Foerster and Ludwig von Bertalanffy: you can look these up on the internet if you want to explore the diverse origins of systems theory. However, the most imaginative of all the systemic thinkers was Gregory Bateson. His ideas are probably the most useful ones for doctors.

Bateson was something of a polymath. His original background was in evolutionary biology. (His father was the great Cambridge biologist William Bateson, who coined the word "genetics".) Bateson's own essays covered a huge range of interests including evolution, political theory, religious mysticism, art and psychiatry. ${ }^{1}$ Unfortunately, he was not a very clear writer and his arguments can be hard to follow, but they can all be summed up by a single idea: everything in the world is ultimately connected with everything else, through a complex pattern of interactive loops that never really has any beginning or any end. Because of this fact, all that we can ever perceive of

Correspondence to: Dr John Launer, London Department of Postgraduate Medical Education, Stewart House, 32 Russell Square, London WC1B 5DN, UK; jlauner@londondeanery.ac.uk any phenomenon is only partial and provisional. Moreover, we ourselves as observers are really only a part of the pattern of interactive loops and can never really stand outside it and be entirely objective.

\section{SCHIZOPHRENIC INTERACTION}

A typical example of Bateson's thinking, of particular relevance to doctors, concerns the problem of schizophrenia. Rather than focusing on the individual person with schizophrenia, Bateson preferred to talk about "schizophrenic interaction". While recognising that some people might have a genetic tendency towards schizophrenia, he pointed out that this could only be a small part of a much wider pattern. People behaving in a schizophrenic way would inevitably have an effect on everyone around them, and these effects would then have other effects. For example, family members might react by treating them as weird or dangerous, and this in turn might make them more likely to be so.

Or, in a more complex way, people who showed schizophrenic behaviour might be likely to choose partners who behaved in similar ways to themselves. This would result in children who would have an additional genetic tendency to the same kinds of behaviour, but would also be nurtured in an environment where these kinds of interactions were more common. The social circle around them would then respond in turn by marginalising them, thus adding to their problems. If anyone caught up in such multiple interactions saw a psychiatrist, the problem might then be amplified further, especially if the psychiatrist dwelt only on the abnormal aspects of the person's behaviour and emphasised the diagnosis rather than ever engaging in normal conversation with them.

Bateson argued that this kind of systems thinking was useful not just in clinical fields but in every area of human experience. Let me give a personal example. I regularly visit a café near my workplace where there is a young black waitress whom I used to find very bad tempered. I used to respond in kind by giving her fairly curt requests and not leaving tips. One day I noticed her laughing with a group of young black customers and
I began to wonder if she was grumpy with me because she expected me as an older white man to behave exactly as I was doing: namely being curt and ungenerous. I altered my behaviour and of course she did too. Hopefully we both learned from this, in a way that may make a small contribution to lessening racism, sexism and ageism more widely. Of course we are likely to have less impact on the wider social contexts that determined her previous behaviour and mine, or on the enduring effect of colonialism on black and white people, nor indeed on a range of wider contexts including the relations between males and females, or between in-groups and out-groups across all human cultures. But you never know.

\section{THERAPY WITH FAMILIES}

Bateson was not himself a clinician but he worked for a time with psychologists and psychiatrists. He was particularly influential on a group of people who became the founders of family therapy in the 1950s and '60s. These people started to use his ideas not just with schizophrenia but with alcoholism, behaviour problems in childhood, marital discord and a host of other problems. Instead of seeing any problem as "belonging" to a single individual, they started to focus on how people interacted with each other and how this could make any problem far worse-or far better. They would see patients together with their close relatives, and work with the whole family system to try and understand and help what was going on.

Family therapy has changed in many ways since then, but family therapists continue to use Bateson's ideas. In particular, they tend not to make interpretations about the "cause" of a problem, nor to give advice about how to deal with it. Instead, they ask questions in order to stimulate everyone's interest in the nature of the problem, how it arose, and what is keeping it going. They hope that by thinking about such questions, everyone involved may become more aware of their own contribution towards the situation in the "here and now". By working in this way, they aim to help people question the objectivity of their own fixed judgements and labels, and to explore new ways of seeing the world around them and their part in it.

\section{ORGANISATIONAL CONSULTANTS}

Systems thinking is now used very widely in all kinds of human networks. Some organisational consultants use it when 
working with teams or businesses. It is the ideal antidote to simplistic thinking about problems and their solutions. In particular, it can help you to understand how problems nearly always arise through escalating interactions rather than because any single individual is being intentionally difficult. It can also help you to understand that you are highly likely to be part of any problem yourself, as well as part of any potential solution. Perhaps most important, systems thinking can prevent you from making unrealistic interventions into tricky situations, in the naive hope that these will have exactly the effects that you planned, without any further consequences.

Once you reorient yourself towards systems thinking, one of the things that you start to notice is how much public policy is guided by what one might call systemic naiveté or even systemic illiteracy.
Large scale initiatives in the public sector nearly always come to grief because someone has made a fundamental error in believing that they can make exact predictions about how complex human systems will behave. Alongside that error, there is nearly always an even bigger one: the belief that interventions are neutral in themselves and will not involve any costs, risks or reactions in their own right.

One of my favourite books on this subject is by Jake Chapman and has the title System failure: why governments must learn to think differently.' Chapman argues that systems thinking could provide governments with a good way of finding solutions when dealing with large scale "messes". He proposes that changes in the public sector-where things can get notoriously messy-should not be based on outcomes and targets, but on learning processes instead. He suggests that managers should have an increased tolerance of failure, seek continuous feedback on effectiveness, and try to foster diversity and innovation. Chapman says that the aim of any intervention should be to bring about the minimum change necessary so that innovative, complex behaviours can emerge. According to Chapman, governments and managers should depend far more upon listening than on telling and instructing. It all sounds wonderful, and extraordinarily similar to family therapy.

Competing interests: None declared.

Postgrad Med J 2008;84:447-448.

doi:10.1136/pgmj.2008.072835

\section{REFERENCES}

1. Bateson G. Steps to an ecology of mind. New York: Ballantine, 1972.

2. Chapman J. System failure: why governments must learn to think differently, 2nd ed. Demos: London, 2004. http://www.demos.co.uk/files/systemfailure2.pdf (accessed 20 June 2008)

\section{BMJ Masterclasses}

BMJ Masterclasses are educational meetings designed specifically to meet the learning needs of doctors. They help doctors keep up to date with the latest evidence and recent guidelines in major clinical areas, enabling them to use the latest evidence to make better decisions. The latest evidence, recent guidelines and best practice are delivered in an interactive and informative manner by leading experts. The speakers are specifically chosen as highly-skilled communicators who can authoritatively enthuse the audience and interpret the latest research and guidelines into practical tips for busy doctors. BMJ Masterclasses have proved a huge hit with clinicians, with many saying they have influenced their clinical practice.

http://masterclasses.bmj.com/ 